\title{
Multimodal Treatment Patterns for Osteoarthritis and Their Relationship to Patient-Reported Pain Severity: A Cross-Sectional Survey in the United States
}

This article was published in the following Dove Press journal:

Journal of Pain Research

\author{
Srinivas R Nalamachu' \\ Rebecca L Robinson ${ }^{2}$ \\ Lars Viktrup (D) $^{3}$ \\ Joseph C Cappelleri $\mathbb{D}^{4}$ \\ Andrew G Bushmakin ${ }^{4}$ \\ Leslie Tive ${ }^{5}$ \\ Jennifer Mellor ${ }^{6}$ \\ Niall Hatchell $\mathbb{D}^{6}$ \\ James Jackson $\mathbb{D I}^{6}$ \\ 'Mid America PolyClinic, Overland Park, \\ KS, USA; ${ }^{2}$ Patient Outcomes and Real- \\ World Evidence, Eli Lilly and Company, \\ Indianapolis, IN, USA; ${ }^{3}$ Lilly Bio- \\ Medicines Core Team, Eli Lilly and \\ Company, Indianapolis, IN, USA; \\ ${ }^{4}$ Statistics, Pfizer Inc, Groton, CT, USA; \\ ${ }^{5}$ Medical Affairs, Pfizer Inc, New York, \\ NY, USA; ${ }^{6}$ Real World Research, Adelphi \\ Real World, Bollington, Cheshire, UK
}

Correspondence: Rebecca L Robinson Eli Lilly and Company, Lilly Research Labs, Lilly Corporate Center, Indianapolis, IN 46285, USA

Tel + | 317-224-5833

Fax + I 317-277-0490

Email rlrobinson@lilly.com
Purpose: The purpose of this study was to assess how patient-reported pain is related to osteoarthritis (OA) treatment patterns in routine clinical practice.

Patients and Methods: Data were collected between February and May 2017 from 153 United States (US) primary care physicians, rheumatologists, and orthopedic surgeons. Each invited up to nine consecutive patients to rate their OA pain in the last week. Physicians provided demographic, clinical, and treatment information for patients, including nonpharmacologic therapies ever recommended, currently recommended over-the-counter (OTC) medications, and currently and ever prescribed medications for the management of OA. Findings for patients with mild $(0-3)$, moderate (4-6), and severe current pain (7-10) were compared using appropriate statistics.

Results: Among the 841 patients (61\% female; mean 65 years; $57 \%$ knee OA), $45 \%$ reported mild, 36\% moderate, and 19\% severe current OA pain. Current treatment modalities differed by pain severity $(P<0.05)$. Most patients $(70 \%)$ had been recommended nonpharmacologic therapy and $40 \%$ were currently recommended OTC medications. More patients with moderate $(81 \%)$ or severe pain (78\%) currently received prescription medications, with or without nonpharmacologic therapy, versus those with mild pain (67\%). Overall, $47 \%$ of patients currently received just one prescription drug, while $49 \%$ had received one prescription drug ever. Nonsteroidal antiinflammatory drugs (NSAIDs) were the most common current (58\%) and ever received (88\%) prescriptions. Current NSAID prescriptions were not associated with pain severity. Acetaminophen recommendations, opioid prescriptions (current and ever), and multiple prescription medications tried were numerically highest in the severe pain group (all $P<0.05$ by pain severity). In all groups, $>80 \%$ of treatment switches were due to lack of efficacy.

Conclusion: Real-life treatment patterns for OA in the US are significantly associated with current patient-reported pain. Combining nonpharmacologic and pharmacologic treatments is common but higher pain ratings are associated with multiple failed prescription treatments. Current use of acetaminophen and opioids, but not NSAIDs, increases alongside pain severity. Keywords: nonprescription drugs, prescription drugs, therapeutics, pain management, practice patterns, physicians

\section{Introduction}

Osteoarthritis (OA) is the most common form of arthritis in the United States (US), and its prevalence is increasing. ${ }^{1-3}$ Pain is the hallmark symptom of OA, often driving individuals to seek medical attention and contributing to functional limitations, reducing quality of life, and increasing the overall healthcare burden. ${ }^{1-3}$ Joint 
pain in OA is complex and incompletely understood, particularly as pain does not consistently correlate with observed structural joint damage. ${ }^{4}$ It can be a product of multiple factors, including peripheral/central sensitization and individual patient characteristics. ${ }^{4}$ These factors can further complicate the treatment of OA.

As OA can involve multiple joints and is progressive in nature, treatment is often dynamic and long term. Clinical guidelines for the management of $\mathrm{OA}$ are joint-specific and increasingly personalized, taking into account each patient's comorbidity profile, concerns, goals, and personal situation. ${ }^{5-9}$ Treatment for OA is generally focused on alleviating pain and reducing functional impairment through nonpharmacologic, pharmacologic, and surgical interventions. ${ }^{10}$

The data in the presented treatment analysis were collected in 2017 as part of the Adelphi Disease Specific Programme (DSP). ${ }^{11}$ At the time, both the Osteoarthritis Research Society International (OARSI) ${ }^{5,7}$ and American College of Rheumatology $(\mathrm{ACR})^{6}$ guidelines for the nonsurgical management of hip and knee OA strongly recommended aerobic/resistance land-based exercise, water-based exercise, and weight loss (for overweight patients only) as appropriate nonpharmacologic therapies. This was to be conducted alongside the receipt of medications, if required, including acetaminophen (for those without comorbidities), oral nonsteroidal anti-inflammatory drugs (NSAIDs [for those without comorbidities]; preferably topical for the knee), and intra-articular corticosteroids. A number of other nonpharmacologic and pharmacologic approaches are recommended in each of these guidelines.

During this time, opioid prescriptions for patients with $\mathrm{OA}$ were common. ${ }^{12,13}$ There was growing alarm around the continuing opioid epidemic in the US with a rapidly rising incidence of deaths due to overdose. ${ }^{14,15}$ The majority of these deaths were associated with synthetic opioids, and there was increasing co-involvement with prescription opioids. ${ }^{14,15}$ Guidelines for the treatment of hip and knee OA were uncertain around recommending opioids due to the lack of highquality data demonstrating clinically relevant efficacy in this population, the frequent incidence of side effects, and the clear risk of addiction. ${ }^{5-7,16}$ The 2012 ACR guidelines for hip, knee, and hand OA conditionally recommended the use of tramadol, whereas the 2008 OARSI guidelines (hip OA) recommended use of weak opioids in patients refractory to other analgesics and the use of strong opioids only in the management of severe pain. 5,6 OARSI guidelines for knee OA (2014) were "uncertain" about recommending opioids. ${ }^{7}$ Furthermore, the 2016 Centers for Disease Control and Prevention (CDC) guidelines for the use of opioids in the treatment of chronic pain state that nonopioid therapies are preferred and opioids should only be used (cautiously) when benefits outweigh the risks. ${ }^{17}$

There is little published evidence reporting on the multimodal treatment patterns for patients with OA (the combination of prescribed, over-the-counter [OTC], and nonpharmacologic therapies). In view of the importance of pain relief in the treatment of OA and the concern around the use of opioids in this population, this study uniquely assessed the relationship between patient-reported pain severity and physician-determined multimodal treatment patterns in routine clinical practice in the US during 2017.

\section{Patients and Methods Study Design}

This was an observational, noninterventional, cross-sectional study comprising a survey that captured paired data from both physicians and their patients with OA. The methodology associated with the Adelphi DSP has been widely used and has been reported previously. ${ }^{11}$ The DSP methodology was granted a central exception from requiring ethics approval by the Western Institutional Review Board, as it was considered to pose minimal risk to patients and physicians.

\section{Participants}

The current analysis included data for patients visiting physicians for the treatment of OA in US clinical settings between February and May 2017. Physician participants were identified from publicly available lists of healthcare professionals according to predefined selection criteria: 1) practicing in orthopedic surgery, rheumatology, or primary practice; 2) made treatment decisions for at least 10 patients with OA in a typical month. Candidate respondents were screened by telephone, and those who met the predefined eligibility criteria were invited to participate. Physicians completed electronic patient record forms for up to nine consecutive adult ( $\geq 18$ years) patients with a diagnosis of $\mathrm{OA}$. These patients were invited to participate by providing written informed consent and completing companion self-completion forms.

\section{Outcomes}

The study paired physician-derived data with patientreported pain severity. Patients reported their average OArelated pain in the last week using an 11-point numeric rating scale with 0 indicating no pain and 10 indicating the worst possible pain. This was matched to physician- 
completed data including their current primary specialty, patient demographics (age, sex, ethnicity, employment status [question was: "retired/unemployed as a result of their OA?"]) and clinical characteristics (height, weight [for body mass index (BMI)], time since OA diagnosis, affected joints, number of affected joints, location of the most "troublesome" joint, and Charlson Comorbidity Index. ${ }^{18}$ This weighted index is used to estimate the risk of death from multiple comorbid diseases and is commonly used in longitudinal studies. ${ }^{18}$ Definitions for presented outcomes on treatment modalities (nonpharmacologic, OTC, and prescribed medications for OA) are available in Supplementary Table 1.

Nonpharmacologic therapies were captured as those ever recommended to the patient (combining current and any previous). OTC medication recommendations were captured as those currently recommended. Prescription medications are presented as 1) all those currently prescribed including on the day of the office visit; and 2) those ever prescribed for OA, including current prescriptions (as in 1) and any previous prescriptions.

\section{Analysis}

Patient data were grouped by self-reported average pain intensity over the last week on an 11-point numeric rating scale (0-10): mild pain (0-3), moderate pain (4-6), and severe (7-10) pain. These categories have been widely used in clinical studies and routine clinical practice. ${ }^{19}$

Outcomes were summarized for the overall patient population and grouped by pain severity, including demographics and clinical characteristics, current treatment modalities for OA, nonpharmacologic therapies ever recommended for $\mathrm{OA}$, current physician-recommended OTC medications, prescription medications ever prescribed for OA, currently prescribed medications for OA, reasons for switching prescription therapy and duration of use, prior recommendations for nonpharmacologic therapy before the use of medication.

Continuous variables were reported as mean and standard deviation (SD), and compared using analysis of variance. ${ }^{20}$ Categorical variables were described by frequency and percentage, and compared using the Pearson's chi-square test or Fisher-Freeman-Halton test (when an

Table I Patient Demographics and Clinical Characteristics by Current Patient-Reported Pain Severity

\begin{tabular}{|c|c|c|c|c|c|}
\hline & \multicolumn{5}{|c|}{ Current Patient-Reported Pain Severity } \\
\hline & Overall $(\mathrm{N}=\mathbf{8 4} I)$ & Mild $(n=382)$ & Moderate $(n=302)$ & Severe $(n=157)$ & $P$ value \\
\hline Age, years, mean $( \pm S D)$ & $64.6(11.7)$ & $62.4(11.1)$ & $66.2(11.6)$ & $66.9(12.5)$ & $<0.0001$ \\
\hline Female, n (\%) & $512(60.9)$ & $231(60.5)$ & $|7|(56.6)$ & $110(70.1)$ & 0.0194 \\
\hline Ethnicity, White/Caucasian, n (\%) ${ }^{\mathrm{a}}$ & $654(77.8)$ & $286(74.9)$ & $245(8 I . I)$ & $123(78.3)$ & 0.2874 \\
\hline BMI, mean $( \pm S D)$ & $28.7(5.8)$ & $27.7(5.1)$ & $29.1(5.6)$ & $30.3(7.2)$ & $<0.0001$ \\
\hline \multicolumn{6}{|l|}{ BMI category, n (\%) } \\
\hline Underweight $(<18.5)$ & $6(0.7)$ & $3(0.8)$ & $3(1.0)$ & 0 & \\
\hline Healthy weight (I8.5-25) & $230(27.3)$ & $113(29.6)$ & $75(24.8)$ & $42(26.8)$ & \\
\hline Overweight (25-29) & $308(36.6)$ & $163(42.7)$ & $103(34.1)$ & $42(26.8)$ & 0.0002 \\
\hline Obese $(\geq 30)$ & $297(35.3)$ & $103(27.0)$ & $|2|(40.1)$ & $73(46.5)$ & \\
\hline $\mathrm{n}$ & 435 & 213 & 154 & 68 & \\
\hline Time since diagnosis, years, mean $( \pm S D)$ & $2.3(3.8)$ & $1.9(2.9)$ & $2.6(4.4)$ & $3.0(4.8)$ & 0.0686 \\
\hline Number of affected joints, mean $( \pm S D)$ & $3.1(2.5)$ & $2.7(2.1)$ & $3.4(2.7)$ & $3.6(2.8)$ & $<0.0001$ \\
\hline \multicolumn{6}{|l|}{ Affected joints (>25\% overall), n (\%) } \\
\hline Knee & $479(57.0)$ & $200(52.5)$ & $178(58.9)$ & $101(64.3)$ & 0.0264 \\
\hline Back & $312(37.1)$ & $106(27.7)$ & $128(42.4)$ & $78(49.7)$ & $<0.0001$ \\
\hline Hip & $268(31.9)$ & $97(25.4)$ & $109(36.1)$ & $62(39.5)$ & 0.0009 \\
\hline Charlson Comorbidity Index, mean $( \pm S D)$ & $0.4(0.8)$ & $0.3(0.6)$ & $0.4(0.9)$ & $0.5(0.9)$ & 0.0054 \\
\hline
\end{tabular}

Notes: Data were not available for all outcomes for all patients. ${ }^{a}$ Additionally: II.2\% African American, $6.2 \%$ Hispanic/Latino, $2.7 \%$ Asian, $0.5 \%$ Middle Eastern, $0.6 \%$ mixed race, $0.5 \%$ Chinese, and $0.6 \%$ Native American. Continuous variables compared using analysis of variance. Categorical variables compared using the Pearson's chi-square test. Abbreviations: BMI, body mass index; SD, standard deviation. 
expected cell count was less than 5). ${ }^{20,21}$ All data were managed and analyzed using SPSS version 7.5 (SPSS Inc., Chicago, IL) and Stata version 14.1 (StataCorp, College Station, TX, US).

\section{Results}

\section{Patient Demographic and Clinical Characteristics}

A total of 841 patients were included in this analysis, identified by 153 physicians. Their demographics and clinical characteristics are shown in Table 1. Most patients (59.2\%) were managed by primary care physicians, with rheumatologists and orthopedists contributing $25.9 \%$ and $14.9 \%$ of patients, respectively. The most commonly affected joint was the knee $(57.0 \%)$, followed by the back (37.1\%) and hip (31.9\%). The knee was reported by the physician to be the most "troublesome" joint $(43.0 \%$; back $21.3 \%$; hip $18.0 \%$ ). Overall, $6.1 \%$ of patients were unemployed/retired due to their OA.

Of the 841 patients, $382(45.4 \%)$ patients reported mild current pain, 302 (35.9\%) moderate pain, and 157 (18.7\%) severe pain. Age, sex, BMI category, number of affected joints, and Charlson Comorbidity Index were all significantly associated with patient-reported pain severity (Table 1), whereas time since diagnosis was not (mean: 2 years).

Age, BMI, number of affected joints, proportions of patient with knee, back, or hip involvement, and Charlson Comorbidity Index all appeared higher in patients with severe pain than in those with moderate or mild pain. There was also a higher proportion of female patients in the severe pain group than in the moderate or mild pain groups.

\section{Current Multimodal Treatment}

\section{Combinations}

There was a significant association between current treatment modality combinations and current patient-reported pain severity $(P=0.0021)$. Most patients $(57.6 \%)$ were prescribed prescription medications along with nonpharmacologic therapy recommendations (Figure 1). Fewer received medication prescriptions only $(16.5 \%)$, or recommendations for nonpharmacologic treatment only (19.9\%). Higher proportions of patients with moderate or severe pain received prescription medications than those with mild pain, and fewer received no treatment.

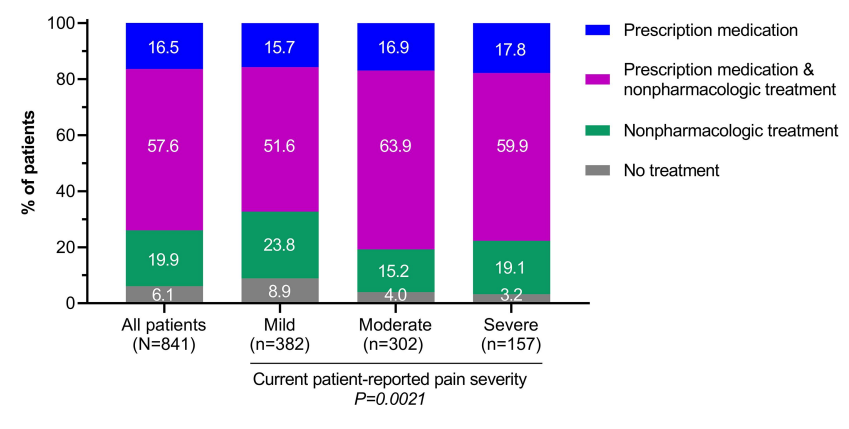

Figure I Percentage of Patients Currently Utilizing Nonpharmacologic and Pharmacologic Treatment by Pain Severity. Current treatment recommendations were collected from the treating physician. Patients reported their current osteoarthritis joint pain on an $1 \mathrm{I}$-point scale; $0-3=$ mild; 4-6=moderate; $7-10=$ severe. $P$ value derived from the Pearson's chi-squared test.

\section{Recommendations for Nonpharmacologic Therapies}

Physicians reported having a discussion (at any time) about nonpharmacologic therapies with $69.6 \%$ of patients. Recommendations for weight loss, physical therapy, avoidance of painful activities, use of a walking aid, and use of walkers and wheelchairs were all significantly associated with current patient-reported pain severity (Figure 2).

A numerically higher proportion of patients with severe pain $(79.6 \%)$ had discussed nonpharmacologic therapies with their physician than those with moderate $(66.9 \%)$ or mild $(67.5 \%)$ pain. Fitness/exercise regimens, weight loss, and use of physical therapy were the three most common recommendations.

The timing of nonpharmacologic therapy introduction was significantly associated with current pain severity ( $P=0.0252$ ). Overall, $25.9 \%$ of patients with severe pain had tried at least one nonpharmacologic therapy before drug treatment compared with $14.5 \%$ and $15.1 \%$ of patients with mild or moderate pain, respectively.

\section{Currently Recommended Over-the- Counter Medications}

Most patients (59.9\%) were not currently recommended to take OTC medications for OA by their physician, and this was not significantly different across pain severity groups (Table 2; 40.1\% were currently recommended OTC medications).

The most commonly recommended OTC medications for OA are shown in Table 2. Naproxen was recommended to a numerically higher proportion of patients with mild pain $(26.6 \%)$ than those with moderate 


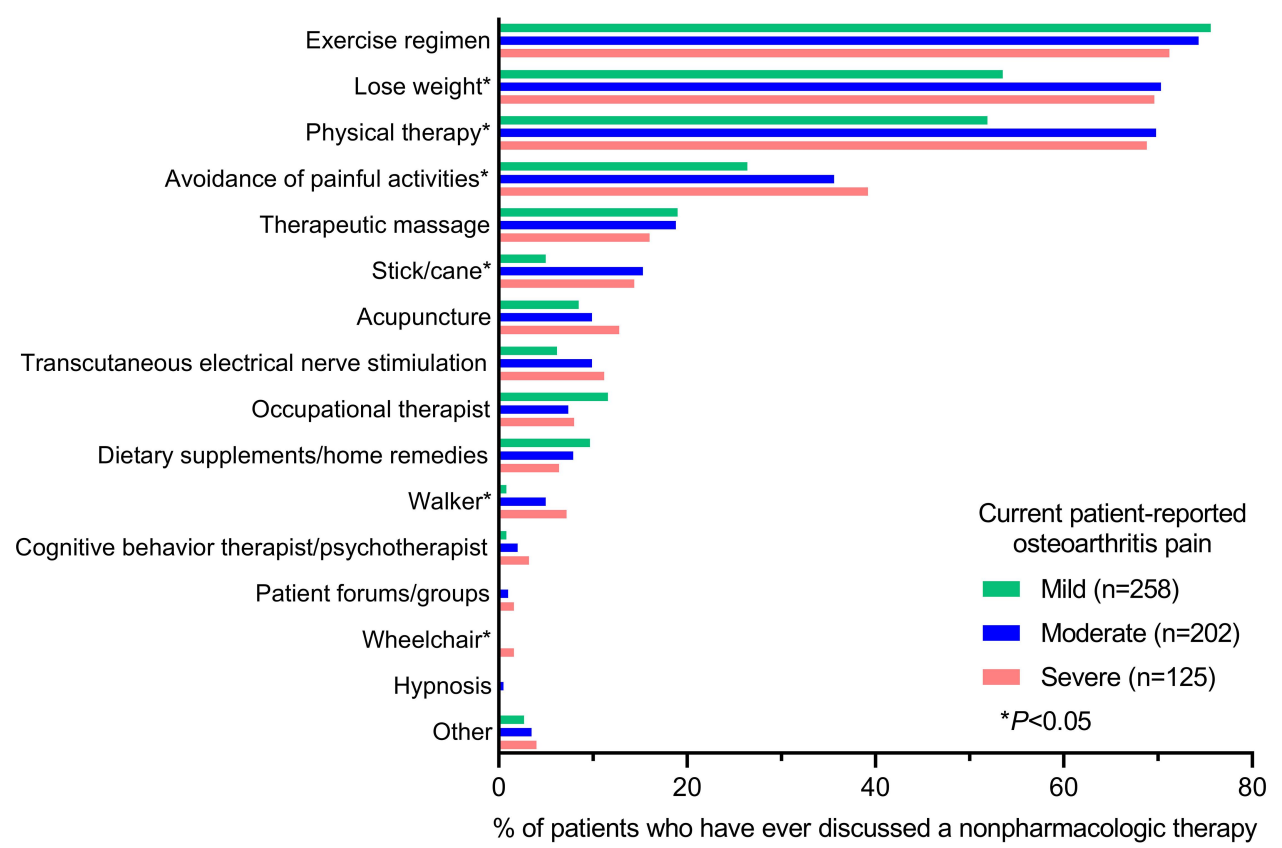

Figure 2 Nonpharmacologic Therapy Recommendations by Current Patient-Reported Pain Severity. Nonpharmacologic recommendations have been made (at any time, including the day of the office visit) to $67.5 \%$ of patients with mild, $66.9 \%$ with moderate, and $79.6 \%$ with severe current osteoarthritis pain (585/84I [69.6\%] overall). $P$ values compared across pain severity groups using the Pearson's chi-squared test or the Fisher-Freeman-Halton test $(F F H)$ : lose weight $P=0.0002$, physical therapy $P=0.000 \mathrm{I}$, avoidance of painful activities $P=0.019 \mathrm{I}$, stick/cane $P=0.0005$, walker $P=0.0029(\mathrm{FFH})$, wheelchair $P=0.0249$ (FFH). All others were $P<0.05$ (cognitive behavior therapist/psychotherapist, hyponosis, patient forums/groups by FFH).

$(11.5 \%)$ or severe pain $(9.8 \%)$. Conversely, acetaminophen recommendations were most common among patients with severe pain $(65.6 \%$ vs $56.6 \%$ moderate and $42.9 \%$ mild). Further statistical analysis showed recommendations for both naproxen and acetaminophen were significantly associated with patient-reported pain severity.

\section{Medications Ever Prescribed}

Overall, $84.4 \%$ of patients had ever received a prescription for their OA pain (Table 3). NSAIDs were the most commonly prescribed medication (88.0\% overall). The proportion of patients who had received an NSAID prescription was highest among those with moderate current pain and lowest among those with severe pain. Similar trends were observed for glucosamine/chondroitin prescriptions. This was in contrast with findings for opioids, which had been most prescribed to patients with severe pain. The proportion of patients who had ever received opioids increased alongside current pain severity.

Current pain severity was statistically associated with prescriptions for opioids (overall, strong, and weak), glucosamine/chondroitin, and NSAIDs. There was also a significant association between current pain severity and the number of prescription drugs that the patient had ever taken, as there was for never having received a prescription for OA (Tables 3 and 4).

Just over half of all patients (51.5\%) had received more than one type of medication for OA to date (Table 3). Overall, $28.7 \%$ of patients with severe current pain had tried $\geq 3$ medications, compared with $19.6 \%$ of those with moderate and $9.5 \%$ of those with mild pain. Conversely, $59.1 \%$ of patients with mild pain had tried just one medication.

Physicians cited "lack of efficacy" as the reason for switching to second- (82.5\%) and third-line (85.3\%) therapies, with no association with current pain severity (Table 3). The mean (SD) physician-reported duration of therapy for all treatment lines was 63.9 (63.0) weeks, and this duration was associated with current pain severity ( $P=0.0018$; Table 3 ), being longest in those with moderate current pain.

\section{Current Prescription Medications}

Medications were currently prescribed to $74.1 \%$ of patients to treat their OA: $46.8 \%$ received monotherapy, $16.1 \%$ received two concomitant prescriptions, and $11.2 \%$ received three or more (Table 4). A further $10.3 \%$ had 
Table 2 Physician-Reported Recommendations for OTC Medications by Current Patient-Reported Pain Severity

\begin{tabular}{|c|c|c|c|c|c|}
\hline & \multicolumn{4}{|c|}{ Current Patient-Reported Pain } & \multirow[t]{2}{*}{$P$ value } \\
\hline & Overall $(\mathbf{N}=84 I)$ & Mild $(n=382)$ & Moderate $(n=302)$ & Severe $(n=157)$ & \\
\hline \multicolumn{6}{|c|}{ Physician recommended that the patient currently takes OTC medication for their osteoarthritis, $\mathbf{n}(\%)$} \\
\hline Yes & $337(40.1)$ & $158(4 \mid .4)$ & $116(38.4)$ & $63(40.1)$ & 0.7365 \\
\hline No & $504(59.9)$ & $224(58.6)$ & $186(61.6)$ & $94(59.9)$ & \\
\hline \multicolumn{6}{|c|}{ Type of OTC medication currently recommended } \\
\hline $\mathrm{n}$ & 328 & 154 & 113 & 61 & \\
\hline Acetaminophen, n (\%) & $170(5 \mid .8)$ & $66(42.9)$ & $64(56.6)$ & $40(65.6)$ & 0.0049 \\
\hline Ibuprofen, n (\%) & $60(18.3)$ & $31(20.1)$ & $18(15.9)$ & II (I8.0) & 0.6795 \\
\hline Naproxen, n (\%) & $60(18.3)$ & $41(26.6)$ & $13(11.5)$ & $6(9.8)$ & 0.0011 \\
\hline Glucosamine, $n(\%)$ & $21(6.4)$ & $8(5.2)$ & $10(8.8)$ & $3(4.9)$ & 0.4214 \\
\hline Other, n (\%) & $17(5.2)$ & $8(5.2)$ & $8(7.1)$ & I (I.6) & 0.3033 \\
\hline
\end{tabular}

Notes: Disparity between the number of patients to whom OTC medications were recommended $(n=337$ ) and the number of OTC medications according to type ( $\mathrm{n}=328$ ) reflects that some physicians did not state what type of medication was recommended. $P$ values compared across pain severity groups using the Pearson's chi-squared test or the Fisher-Freeman-Halton test ("glucosamine" and "other").

Abbreviation: OTC, over-the-counter.

previously been prescribed $\geq 1$ medication but had no active prescriptions.

There was a significant association between pain severity and having no current prescriptions (comprising patients who have never had a prescription and those with only discontinued prescriptions), having a current prescription, and the number of currently prescribed medications.

NSAIDs were the most common current prescription medication for OA in all pain severity groups (Table 4). Opioids (overall, strong, and weak), non opioid analgesics other than NSAIDs (ie, prescription acetaminophen or capsaicin), corticosteroids, and glycosaminoglycans were significantly associated with pain severity.

Substantially higher proportions of patients with severe and moderate pain were prescribed opioids than those with mild pain. Use of nonopioid analgesics other than NSAIDs, corticosteroids, and glycosaminoglycans was highest among patients with moderate pain.

\section{Discussion}

In this 2017 survey of patients actively seeking OA care in the US, $54.6 \%$ reported moderate or severe current pain. A number of treatment patterns were most common among patients with severe pain, notably, any recommendations for nonpharmacologic therapy, recommendation for OTC acetaminophen, ever having received a prescription for OA pain, $\geq 3$ prescription medications ever tried, and opioid prescriptions (currently or ever received). Separate statistical analysis confirmed that these treatment patterns were significantly associated with the severity of current pain.

Nonpharmacologic therapies are increasingly recognized as important adjuncts for the management of OA of all severities, and have been included in treatment guidelines for many years. ${ }^{5-9}$ In this study, nonpharmacologic therapies had been discussed with higher proportions of patients with severe current pain (79.6\%) than those reporting moderate $(66.9 \%)$ or mild pain $(67.5 \%)$. The mean time since diagnosis of 2-3 years was not significantly different between groups. The three most commonly discussed nonpharmacologic therapies (weight loss, exercise regimens, and physical therapy) aligned well with the treatment guidelines available at the time..$^{5-7}$ Obesity is a well-established risk factor for $\mathrm{OA}^{22}$ In this study, $46.5 \%$ of patients with severe pain were obese (BMI $\geq 30$ ) and BMI was significantly associated with current OA pain. Interestingly, avoidance of painful activities was the fourth most commonly recommended nonpharmacologic therapy but does not feature in clinical guidelines, and the use of walking aids (sticks/ canes/walkers) were not commonly recommended despite being mentioned in the guidelines and being relatively easy to obtain.

The level of current prescription medication use in this study was high (74.1\%). Data from the US Osteoarthritis Initiative (OAI) database of patients with symptomatic and radiographically confirmed knee OA showed that only $30.1 \%$ of patients reported prescription medication use in 
Table 3 Physician-Reported Medications Ever Prescribed by Current Patient-Reported Pain Severity

\begin{tabular}{|c|c|c|c|c|c|}
\hline & \multicolumn{4}{|c|}{ Current Patient-Reported Pain } & \multirow[t]{2}{*}{$P$ value } \\
\hline & $\begin{array}{l}\text { Overall } \\
(\mathbf{N}=\mathbf{8 4 I})\end{array}$ & $\begin{array}{l}\text { Mild } \\
(n=382)\end{array}$ & $\begin{array}{l}\text { Moderate } \\
(n=302)\end{array}$ & $\begin{array}{l}\text { Severe } \\
(n=157)\end{array}$ & \\
\hline \multicolumn{6}{|l|}{ Medications ever prescribed for osteoarthritis, $\mathbf{n}(\%)$} \\
\hline Any & $710(84.4)$ & $296(77.5)$ & 27I (89.7) & I43 (9l. $)$ & $<0.0001$ \\
\hline $\mathrm{NSAIDs}^{\mathrm{a}}$ & $625(88.0)$ & $26 \mid(88.2)$ & $250(92.3)$ & $114(79.7)$ & 0.0009 \\
\hline Other non opioid analgesics & $216(30.4)$ & $81(27.4)$ & $92(33.9)$ & $43(30.1)$ & 0.2337 \\
\hline Any opioid & $203(28.6)$ & $53(17.9)$ & $90(33.2)$ & $60(42.0)$ & $<0.0001$ \\
\hline Weak opioid & $163(23.0)$ & $43(14.5)$ & $75(27.7)$ & $45(31.5)$ & $<0.0001$ \\
\hline Strong opioid & $39(5.5)$ & $8(2.7)$ & $17(6.3)$ & $14(9.8)$ & 0.0073 \\
\hline Corticosteroids ${ }^{b}$ & $103(14.5)$ & $34(11.5)$ & $42(15.5)$ & $27(18.9)$ & 0.1004 \\
\hline Glucosamine or chondroitin ${ }^{b}$ & $70(9.9)$ & $23(7.8)$ & $38(14.0)$ & $9(6.3)$ & 0.0124 \\
\hline Viscosupplements & $31(4.4)$ & $12(4.1)$ & $10(3.7)$ & $9(6.3)$ & 0.4408 \\
\hline Other ${ }^{c}$ & $36(5.1)$ & II (3.7) & $13(4.8)$ & $12(8.4)$ & 0.1082 \\
\hline Duration of use for all treatment lines, $n$ & 709 & 296 & 270 & 143 & 0.0018 \\
\hline Mean $( \pm S D)$, weeks & $63.9(63.0)$ & $56.8(48.1)$ & $74.6(80.4)$ & $58.5(48.6)$ & \\
\hline \multicolumn{6}{|c|}{ Number of different prescribed drug treatment regimens ever received for osteoarthritis, $n$ (\%) } \\
\hline $\mathrm{n}$ & 710 & 296 & 271 & 143 & \\
\hline I & $344(48.5)$ & $175(59.1)$ & $119(43.9)$ & $50(35.0)$ & \\
\hline 2 & $244(34.4)$ & $93(31.4)$ & $99(36.5)$ & $52(36.4)$ & $<0.0001$ \\
\hline 3 or more & $122(17.2)$ & $28(9.5)$ & $53(19.6)$ & $4 \mid(28.7)$ & \\
\hline $\begin{array}{l}\text { Patients switching to } 2 \text { nd regimen due to "lack of } \\
\text { efficacy," n (\%) }\end{array}$ & $273(82.5)$ & 94 (83.2) & 115 (82.7) & $64(81.0)$ & 0.9218 \\
\hline $\begin{array}{l}\text { Patients switching to } 3 \text { rd regimen due to "lack of } \\
\text { efficacy," } n(\%)^{d}\end{array}$ & $93(85.3)$ & $20(83.3)$ & $42(85.7)$ & $31(86.1)$ & 0.9514 \\
\hline
\end{tabular}

Notes: ${ }^{a}$ Traditional NSAIDs, cyclooxygenase-2 inhibitors, or NSAIDs given with proton pump inhibitors. 'Includes intraarticular and oral use. Includes medications used by $<5 \%$ of patients. 'Patients who had switched medications and showed response to medication use. $P$ values compared across pain severity groups using the Pearson's chisquared test.

Abbreviation: NSAID, nonsteroidal anti-inflammatory drugs.

the 30 days before survey (published in 2013). ${ }^{23}$ In a 2007 study of US MarketScan ${ }^{\circledR}$ claims databases, $87 \%$ of patients with OA had received prescription pain medication in the last 12 months. ${ }^{24}$ Our results are more closely comparable with the claims data than with the US OAI data. This may be because patients in our study were actively seeking medical care for their OA.

In our study, most patients (57.6\%) were currently on a treatment regimen consisting of $\geq 1$ prescribed medication and $\geq 1$ nonpharmacologic therapy, and there was a significant association between current treatment modalities and patient-reported pain. Patients with more severe pain appeared more likely to receive both modalities together, or to receive just prescription medications. The majority of all patients currently received $\leq 1$ prescription medications, irrespective of pain level. However, patients with severe pain appeared to have tried more prescribed medication regimens, which more often included opioids. Similar to the findings of Kingsbury $(2013)^{23}$ in patients with knee OA, prescription therapy switching appeared to be common in our study, and $>80 \%$ of patients were switched to second- or third-line regimens due to lack of efficacy. These findings suggest that some patients found their pain difficult to address and may be candidates for joint replacement surgery or novel therapeutics.

Treatment of OA with acetaminophen and/or NSAIDs was common and recommended in treatment guidelines applicable at the time, despite some notes of caution. ${ }^{5-7}$ In this study, current recommendations for OTC acetaminophen were significantly related to patient-reported pain severity. Numerically higher proportions of patients with severe pain were recommended acetaminophen than those with moderate or mild pain. Current recommendations for OTC ibuprofen (18.3\%) and prescriptions for NSAIDs 
Table 4 Physician-Reported Present Prescription Medications by Current Patient-Reported Pain Severity

\begin{tabular}{|c|c|c|c|c|c|}
\hline \multirow[t]{2}{*}{ n (\%) } & \multicolumn{4}{|c|}{ Current Patient-Reported Pain } & \multirow[t]{2}{*}{$P$ value } \\
\hline & $\begin{array}{l}\text { Overall } \\
(N=84 I)\end{array}$ & $\begin{array}{l}\text { Mild } \\
(n=382)\end{array}$ & $\begin{array}{l}\text { Moderate } \\
(n=302)\end{array}$ & $\begin{array}{l}\text { Severe } \\
(n=157)\end{array}$ & \\
\hline $\begin{array}{l}\text { Currently prescribed treatments for } \\
\text { osteoarthritis }\end{array}$ & $623(74.1)$ & $257(67.3)$ & $244(80.8)$ & $122(77.7)$ & 0.0002 \\
\hline No current prescriptions & $218(25.9)$ & $125(32.7)$ & $58(19.2)$ & $35(22.3)$ & 0.0002 \\
\hline Only discontinued prescriptions & $87(10.3)$ & $39(10.2)$ & $27(8.9)$ & $21(13.4)$ & 0.3321 \\
\hline Never prescribed & $|3|(\mid 5.6)$ & $86(22.5)$ & $31(10.3)$ & $14(8.9)$ & $<0.0001$ \\
\hline \multicolumn{6}{|c|}{ Currently prescribed treatments for osteoarthritis by type, $n(\%)$} \\
\hline NSAIDs ${ }^{\mathrm{a}}$ & $484(57.6)$ & $216(56.5)$ & $188(62.3)$ & $80(5 I .0)$ & 0.0583 \\
\hline Other non opioid analgesics & $122(14.5)$ & $42(11.0)$ & $54(17.9)$ & $26(16.6)$ & 0.0287 \\
\hline Any opioid & $168(20.0)$ & $37(9.7)$ & $80(26.5)$ & $51(32.5)$ & $<0.0001$ \\
\hline Strong opioid & $27(3.2)$ & $4(1.0)$ & $10(3.3)$ & $13(8.3)$ & 0.0001 \\
\hline Weak opioid & $108(12.8)$ & $23(6.0)$ & $55(18.2)$ & $30(19.1)$ & $<0.0001$ \\
\hline Corticosteroids ${ }^{b}$ & $64(7.6)$ & $21(5.5)$ & $32(10.6)$ & II (7.0) & 0.0421 \\
\hline Glycosaminoglycans $^{\text {b }}$ & $48(5.7)$ & $15(3.9)$ & $27(8.9)$ & $6(3.8)$ & 0.0103 \\
\hline Viscosupplements & $23(2.7)$ & $10(2.6)$ & $5(1.7)$ & $8(5.1)$ & 0.0987 \\
\hline Other ${ }^{c}$ & $27(3.2)$ & $8(2.1)$ & $12(4.0)$ & $7(4.5)$ & 0.2364 \\
\hline \multicolumn{6}{|c|}{ Number of different prescribed drug treatment regimens currently received specifically for osteoarthritis, $n$ (\%) } \\
\hline None & $218(25.9)$ & $125(32.7)$ & $58(19.2)$ & $35(22.3)$ & \\
\hline I & $394(46.8)$ & $193(50.5)$ & $132(43.7)$ & $69(43.9)$ & \\
\hline 2 & $135(16.1)$ & $39(10.2)$ & $62(20.5)$ & $34(21.7)$ & $<0.0001$ \\
\hline 3 or more & 94 (II.2) & $25(6.5)$ & $50(16.6)$ & $19(12.1)$ & \\
\hline
\end{tabular}

Notes: ${ }^{a}$ Traditional NSAIDs, cyclooxygenase-2 inhibitors, or NSAIDs given with proton pump inhibitors. ${ }^{\mathrm{b}}$ Includes intraarticular and oral use. ${ }^{\mathrm{C}}$ Includes medications used by $<5 \%$ of patients. $P$ values compared across pain severity groups using the Pearson's chi-squared test.

Abbreviation: NSAID, nonsteroidal anti-inflammatory drug.

(57.6\%) were not significantly associated with current pain, while the proportion of patients recommended OTC naproxen declined with increasing pain. There was a significant association between current pain and having ever been prescribed NSAIDs, but this was common in all pain subgroups $(88.0 \%$ of patients overall). These findings may suggest that physicians feel that patients with more severe pain may have exhausted this treatment option.

Pain severity was associated with opioid medication prescriptions in this study, which is consistent with findings from another study with self-reported OA severity. ${ }^{25}$ The proportions of patients currently prescribed an opioid (20.0\%; weak $12.8 \%$ or strong $3.2 \%$ ) were within the broad range of current/recent opioid use identified in other studies of patients with OA in the US $(13 \%-60 \%) .{ }^{12,13,24}$ At the time, opioids were known to have a small therapeutic window for the short-term treatment of $\mathrm{OA}$ and carry a significant risk of addiction-related adverse events, including overdose. ${ }^{16,26,27}$ Treatment guidelines for chronic pain published in 2016 by the CDC cautioned against the use of opioids unless benefits outweighed risk, ${ }^{17}$ and the presiding guidelines for hip and knee OA (all published before 2016) were uncertain around recommending opioids..$^{5-7}$ A notable exception is the conditional recommendation for tramadol in the ACR guidelines, which was based on systematic review evidence. ${ }^{6,28}$ With the exception of tramadol, the observed frequency of opioid prescriptions to patients with OA supports the conclusion that the therapy options available and recommended at the time were potentially suboptimal, leaving physicians little option other than to turn to opioids.

Although no formal estimate of adherence to treatment guidelines was made - aside from opioids - the pattern of prescribed medication seemed somewhat consistent with current recommendations and should be seen in the context of poor adherence to, and uptake of, OA guidelines. ${ }^{29,30}$ Revised treatment guidelines for hip and knee OA have been published since this study and cast further doubt on the use of opioids, NSAIDs, and 
acetaminophen, particularly for patients with comorbidities. ${ }^{8,9}$ However, they are not able to offer significant alternatives for OA management, other than an increased focus on potentially underused nonpharmacologic therapies.

\section{Limitations}

Inferential statistical analyses presented here are exploratory. Our findings should be further investigated in independent patient populations, and it would be of interest to evaluate how the updated OA treatment guidelines have altered clinical practice. While pain is the primary symptom of $\mathrm{OA}^{2}{ }^{2}$ changes in symptoms and structural disease progression are highly variable, individualized, and not necessarily correlated; ${ }^{31}$ yet, they may influence patient care. ${ }^{32,33}$

Although a strength of this study is its relatively large patient sample $(>800)$, this was derived from a relatively small number of geographically spread US physicians $(n=153)$ who may not be representative of OA-treating physicians in general. This may contribute to patient selection bias; however, inclusion of consecutive patients was implemented to reduce such bias. Our patient population is only representative of those currently seeking healthcare for OA. Although symptomatic patients were of greatest interest in this study, it should be recognized that asymptomatic (radiographically confirmed) individuals represent a larger proportion of patients with OA in the US. ${ }^{34}$ Our study patients were also somewhat "self-selected" in that they opted to participate.

All outcomes except current pain were derived from physician responses. To maintain real-world patterns, diagnosis was based on the physician's judgment rather than on a formalized, study-specific, diagnostic checklist. Many outcomes were based on the physician's understanding of the patient's condition, eg, use of medication was determined from physician recommendation (as opposed to patientreported adherence) and may therefore have inherent inaccuracy. Surgical interventions were not included in this assessment.

\section{Conclusions}

This study of real-world patients with OA in 2017 found significant differences in nonpharmacologic, OTC, and prescription therapy recommendations made by treating physicians depending on self-reported patient pain levels. In general, we found reasonable alignment between clinical practice and guideline recommendations for the treatment of OA. Most patients had discussed nonpharmacologic therapies with their physician. Patients with moderate or severe pain appeared more likely to receive treatment in general, have ever discussed a nonpharmacologic therapy or receive prescription medication, and to currently receive prescription medication. Current prescription NSAIDs (most common prescription) did not change with current pain level, but OTC acetaminophen (most common OTC) recommendations and opioid prescriptions increased alongside pain. Furthermore, while most patients had only ever taken one prescription medication, the proportions of patients who had failed multiple prescription regimens ( $>80 \%$ of switching due to lack of efficacy) were numerically highest among patients experiencing severe pain. These findings suggest that there are challenges in the treatment of OA with severe pain.

\section{Abbreviations}

BMI, body mass index; NSAID, nonsteroidal antiinflammatory drug; OA, osteoarthritis; OTC, over-thecounter; SD, standard deviation; US, United States.

\section{Data Sharing Statement}

Data are held by Adelphi Real World.

\section{Acknowledgments}

Editorial support was provided by Jennifer Bodkin, $\mathrm{PhD}$, of Engage Scientific Solutions and was funded by Pfizer and Eli Lilly and Company.

\section{Funding}

This study was sponsored by Pfizer and Eli Lilly and Company. The analysis was conducted independently by Adelphi Real World. Pfizer, Eli Lilly and Company and Adelphi Real World collaborated on study design and interpretation of results. All authors actively collaborated on the study design and interpretation of results; contributed in writing this paper; and have provided final approval of submitted version.

\section{Disclosure}

$\mathrm{SRN}$ is a consultant/speaker and received honorarium from Pfizer and Eli Lilly and Company. RLR and LV are employees and stockholders of Eli Lilly and Company. JCC, AGB, and LT are employees of Pfizer with stock and/or stock options. JM, JJ, and NH are employees of Adelphi Real World, who were paid consultants to Pfizer and Eli Lilly and Company for this study and development of this manuscript. The authors report no other conflicts of interest in this work. 


\section{References}

1. Barbour KE, Helmick CG, Boring M, Brady TJ. Vital signs: prevalence of doctor-diagnosed arthritis and arthritis-attributable activity limitation - United States, 2013-2015. MMWR Morb Mortal Wkly Rep. 2017;66(9):246-253. doi:10.15585/mmwr.mm6609e1

2. Osteoarthritis Research Society International [Internet]. Osteoarthritis: a serious disease. White paper submitted to the U.S. Food and Drug Administration. December 1, 2016. Available from: https://www.oarsi.org/sites/default/files/docs/2016/oarsi_white_ paper_oa_serious_disease_121416_1.pdf. Accessed August 20, 2020.

3. Neogi T. The epidemiology and impact of pain in osteoarthritis. Osteoarthritis Cartilage. 2013;21(9):1145-1153. doi:10.1016/j. joca.2013.03.018

4. Neogi T. Structural correlates of pain in osteoarthritis. Clin Exp Rheumatol. 2017;35 Suppl 107(5):75-78.

5. Zhang W, Moskowitz RW, Nuki G, et al. OARSI recommendations for the management of hip and knee osteoarthritis, part II: OARSI evidence-based, expert consensus guidelines. Osteoarthritis Cartilage. 2008;16(2):137-162. doi:10.1016/j.joca.2007.12.013

6. Hochberg MC, Altman RD, April KT, et al. American College of Rheumatology 2012 recommendations for the use of nonpharmacologic and pharmacologic therapies in osteoarthritis of the hand, hip, and knee. Arthritis Care Res (Hoboken). 2012;64(4):465-474. doi:10.1002/acr.21596

7. McAlindon TE, Bannuru RR, Sullivan MC, et al. OARSI guidelines for the non-surgical management of knee osteoarthritis. Osteoarthritis Cartilage. 2014;22(3):363-388. doi:10.1016/j.joca.2014.01.003

8. Bannuru RR, Osani MC, Vaysbrot EE, et al. OARSI guidelines for the non-surgical management of knee, hip, and polyarticular osteoarthritis. Osteoarthritis Cartilage. 2019;27(11):1578-1589. doi:10.1016/j.joca.2019.06.011

9. Kolasinski SL, Neogi T, Hochberg MC, et al. 2019 American College of Rheumatology/Arthritis Foundation guideline for the management of osteoarthritis of the hand, hip, and knee. Arthritis Rheumatol. 2020;72(2):220-233. doi:10.1002/art.41142

10. McCarberg B, Tenzer P. Complexities in the pharmacologic management of osteoarthritis pain. Curr Med Res Opin. 2013;29(5):539-548. doi:10.1185/03007995.2013.785391

11. Anderson P, Benford M, Harris N, Karavali M, Piercy J. Real-world physician and patient behaviour across countries: Disease-Specific Programmes - a means to understand. Curr Med Res Opin. 2008;24 (11):3063-3072. doi:10.1185/03007990802457040

12. DeMik DE, Bedard NA, Dowdle SB, Burnett RA, McHugh MA, Callaghan JJ. Are we still prescribing opioids for osteoarthritis? $J$ Arthroplasty. 2017;32(12):3578-3582.e3571. doi:10.1016/j. arth.2017.07.030

13. Wright EA, Katz JN, Abrams S, Solomon DH, Losina E. Trends in prescription of opioids from 2003-2009 in persons with knee osteoarthritis. Arthritis Care Res (Hoboken). 2014;66(10):1489-1495. doi:10.1002/acr.22360

14. Rudd RA, Seth P, David F, Scholl L. Increases in drug and opioidinvolved overdose deaths - United States, 2010-2015. MMWR Morb Mortal Wkly Rep. 2016;65(50-51):1445-1452. doi:10.15585/mmwr. mm655051e1

15. Scholl L, Seth P, Kariisa M, Wilson N, Baldwin G. Drug and opioidinvolved overdose deaths - United States, 2013-2017. MMWR Morb Mortal Wkly Rep. 2018;67(5152):1419-1427. doi:10.15585/mmwr. $\mathrm{mm} 675152 \mathrm{e} 1$

16. Krebs EE, Gravely A, Nugent S, et al. Effect of opioid vs nonopioid medications on pain-related function in patients with chronic back pain or hip or knee osteoarthritis pain: The SPACE randomized clinical trial. JAMA. 2018;319(9):872-882. doi:10.1001/jama.2018.0899
17. Dowell D, Haegerich TM, Chou R. CDC guideline for prescribing opioids for chronic pain-United States, 2016. JAMA. 2016;315 (15):1624-1645. doi:10.1001/jama.2016.1464

18. Charlson ME, Pompei P, Ales KL, MacKenzie CR. A new method of classifying prognostic comorbidity in longitudinal studies: development and validation. $J$ Chronic Dis. 1987;40(5):373-383. doi:10.1016/0021-9681(87)90171-8

19. Ornetti P, Dougados M, Paternotte S, Logeart I, Gossec L. Validation of a numerical rating scale to assess functional impairment in hip and knee osteoarthritis: comparison with the WOMAC function scale. Ann Rheum Dis. 2011;70(5):740-746. doi:10.1136/ard.2010.135483

20. Rosner B. Fundamentals of Biostatistics. 8th ed. Boston, MA: Cengage Learning; 2015.

21. Freeman GH, Halton JH. Note on an exact treatment of contingency, goodness of fit and other problems of significance. Biometrika. 1951;38(1-2):141-149. doi:10.1093/biomet/38.1-2.141

22. Zheng H, Chen C. Body mass index and risk of knee osteoarthritis: systematic review and meta-analysis of prospective studies. $B M J$ Open. 2015;5(12):e007568. doi:10.1136/bmjopen-2014-007568

23. Kingsbury SR, Hensor EM, Walsh CA, Hochberg MC, Conaghan PG. How do people with knee osteoarthritis use osteoarthritis pain medications and does this change over time? Data from the Osteoarthritis Initiative. Arthritis Res Ther. 2013;15(5):R106. doi:10.1186/ar4286

24. Le TK, Montejano LB, Cao Z, Zhao Y, Ang D. Healthcare costs associated with osteoarthritis in US patients. Pain Pract. 2012;12 (8):633-640. doi:10.1111/j.1533-2500.2012.00535.x

25. Sadosky AB, Bushmakin AG, Cappelleri JC, Lionberger DR. Relationship between patient-reported disease severity in osteoarthritis and self-reported pain, function and work productivity. Arthritis Res Ther. 2010;12(4):R162. doi:10.1186/ar3121

26. Chou R, Turner JA, Devine EB, et al. The effectiveness and risks of long-term opioid therapy for chronic pain: a systematic review for a National Institutes of Health Pathways to Prevention Workshop. Ann Intern Med. 2015;162(4):276-286. doi:10.7326/m14-2559

27. da Costa BR, Nüesch E, Kasteler R, et al. Oral or transdermal opioids for osteoarthritis of the knee or hip. Cochrane Database Syst Rev. 2014;9:Cd003115. doi:10.1002/14651858.CD003115.pub4

28. Cepeda MS, Camargo F, Zea C, Valencia L. Tramadol for osteoarthritis: a systematic review and metaanalysis. J Rheumatol. 2007;34(3):543-555.

29. Brand CA, Ackerman IN, Bohensky MA, Bennell KL. Chronic disease management: a review of current performance across quality of care domains and opportunities for improving osteoarthritis care. Rheum Dis Clin North Am. 2013;39(1):123-143. doi:10.1016/j.rdc.2012.10.005

30. Nelson AE, Allen KD, Golightly YM, Goode AP, Jordan JM. A systematic review of recommendations and guidelines for the management of osteoarthritis: the chronic osteoarthritis management initiative of the U.S. Bone and Joint Initiative. Semin Arthritis Rheum. 2014;43(6):701-712. doi:10.1016/j.semarthrit.2013.11.012

31. de Rooij M, van der Leeden M, Heymans MW, et al. Prognosis of pain and physical functioning in patients with knee osteoarthritis: a systematic review and meta-analysis. Arthritis Care Res (Hoboken). 2016;68(4):481-492. doi:10.1002/acr.22693

32. Escobar A, Quintana JM, Arostegui I, et al. Development of explicit criteria for total knee replacement. Int J Technol Assess Health Care. 2003;19(1):57-70. doi:10.1017/s0266462303000060

33. Riddle DL, Jiranek WA, Hayes CW. Use of a validated algorithm to judge the appropriateness of total knee arthroplasty in the United States: a multicenter longitudinal cohort study. Arthritis Rheumatol. 2014;66(8):2134-2143. doi:10.1002/art.38685

34. Lawrence RC, Felson DT, Helmick CG, et al. Estimates of the prevalence of arthritis and other rheumatic conditions in the United States: part II. Arthritis Rheum. 2008;58(1):26-35. doi:10.1002/ art.23176 
Journal of Pain Research

Dovepress

\section{Publish your work in this journal}

The Journal of Pain Research is an international, peer reviewed, open access, online journal that welcomes laboratory and clinical findings in the fields of pain research and the prevention and management of pain. Original research, reviews, symposium reports, hypothesis formation and commentaries are all considered for publication. The manuscript

Submit your manuscript here: https://www.dovepress.com/journal-of-pain-research-journa management system is completely online and includes a very quick and fair peer-review system, which is all easy to use. Visit http:// www.dovepress.com/testimonials.php to read real quotes from published authors. 